\title{
SENTIDO Y COMPRENSIÓN DE LA HISTORIA DEL PENSAMIENTO POLÍTICO*
}

\author{
Quentin Skinner \\ Leonidas Montes
}

Junto con relatar los orígenes de su pasión por la historia, en esta entrevista con Leonidas Montes el destacado historiador inglés Quentin Skinner se refiere a su visión del estudio de las ideas políticas del pasado. Reseña aquí su planteamiento de que la tarea del historiador es la reconstrucción del contexto intelectual en el cual están inmersos y escriben los autores. A su vez, entre otros tópicos, esboza su opinión sobre el concepto de libertad en la teoría republicana y en la teoría liberal,

Quentin Skinner. Historiador. Barber Beaumont Professor of the Humanities, Queen Mary, Universidad de Londres, y Regius Professor of Modern History de la Universidad de Cambridge. Figura destacada de la Escuela de Cambridge en el estudio del pensamiento político. Ha sido autor y coautor de más de veinte libros y de otras numerosas publicaciones académicas. Su The Foundations of Modern Political Thought (1978) es un clásico. Ha obtenido los premios Isaiah Berlin de la Political Studies Association, el Premio David Easton y el Bielefelder Wissenschaftspreis, y ha sido distinguido como Doctor Honoris Causa por las universidades de Oxford y Harvard. En 2009 fue nombrado Miembro Académico Honorario de la Universidad Adolfo Ibáñez.

Leonidas Montes. Decano de la Escuela de Gobierno de la Universidad Adolfo Ibáñez (UAI) y Consejero del Centro de Estudios Públicos.

* Entrevista realizada el 27 de octubre de 2009 en Santiago de Chile. Traducción al castellano de Estudios Públicos.

Véase también en esta edición el ensayo del profesor Skinner "Una genealogía del Estado moderno". 
sobre sus coincidencias y diferencias, y hace presente sus dudas respecto de la conveniencia de etiquetar estas posiciones rivales como "republicana" y "liberal" respectivamente. Por último, subraya la importancia del sentido filosófico en los estudios históricos, pues, a su juicio, lo que más interesa es que éstos nos provean de un entendimiento que nos permita reflexionar sobre nuestras dificultades actuales con nuevos ojos.

Palabras clave: historia; historia de las ideas políticas; teoría liberal; teoría republicana; concepto de libertad; Quentin Skinner.

Leonidas Montes: ¿Podría contarnos por qué siguió una carrera académica y por qué decidió estudiar historia en Cambridge?

Quentin Skinner: En el colegio me animaron para que postulara tanto a Oxford como a Cambridge, pero la razón por la que preferí Cambridge fue principalmente de carácter familiar. Mi hermano mayor había estudiado medicina en Gonville y Caius College, de la Universidad de Cambridge, y yo simplemente lo seguí y elegí el mismo college.

Decidí estudiar historia en la universidad en parte porque había sido una materia muy importante de mi formación escolar, junto con la literatura (tanto clásica como moderna), y porque siempre me gustó mucho. Pero la razón principal de mi decisión — que de hecho la hizo aparecer no tanto como una opción sino más bien como algo resuelto- fue la suerte de haber tenido en el colegio un profesor de historia brillante e imaginativo. Más tarde, en Cambridge, fui alumno de varios profesores talentosos, pero nunca de alguien que me abriera los ojos a la vida de la mente en forma tan integral.

Cuando llegué a Cambridge ya sabía que quería ser profesor. Al terminar el colegio, antes de entrar a la universidad, hice clases durante un año en una secundaria pública cerca de Londres. Me resultó muy duro, ya que las clases tenían muchos alumnos, yo no tenía experiencia enseñando y en algunos cursos los alumnos y alumnas apenas eran tres o cuatro años más jóvenes que yo. De modo que cuando llegué a Cambridge ya empezaba a tener algunas dudas de si era una buena decisión ser profesor de colegio. Pero cuando se me presentó la oportunidad de quedarme en Cambridge y convertirme en profesor universitario, me pareció la solución ideal. La tomé con entusiasmo y, de hecho, luego 
hice casi toda mi carrera en Cambridge. Nunca he dejado de considerarme, más que nada, como un profesor.

L. M.: ¿Cuáles serían las tres o cuatro figuras más influyentes en su carrera académica y por qué?

Q. S.: Ya mencioné a mi profesor de historia en el colegio, que se llamaba John Eyre. Él hizo que me diera cuenta a temprana edad de que la historia podía ser una materia no sólo de importancia académica sino también moral. Él sentía también una profunda pasión por la literatura y me hizo notar la importancia, si quería ser historiador, de aprender a escribir bien. Su ideal de buena escritura era que uno debería ser capaz de explicar, incluso los problemas más complejos, en términos simples y claros. Escribir con ese tipo de lucidez siempre ha sido mi aspiración más alta, pero no creo haber alcanzado nunca los estándares que él me fijó.

Cuando estaba en el pre-grado fue el teórico político Peter Laslett quien más influyó en mí. Fue muy emocionante cuando se publicó su edición de Two Treatises of Government (Dos Ensayos sobre el Gobierno Civil), de John Locke, justo cuando yo estaba en segundo año y empezaba mis estudios de historia del pensamiento político. Me impresionó en particular la forma en que Laslett mostraba cómo la célebre obra de Locke había surgido de una serie de debates políticos de su época y cómo Locke los había abordado.

Tenía poco más de treinta años cuando me trasladé desde Cambridge al Instituto de Estudios Avanzados, de la Universidad de Princeton, donde permanecí cuatro años. En Princeton había tres académicos con cuyas publicaciones ya estaba familiarizado, a los que entonces llegué a conocer personalmente y de quienes aprendí mucho. Uno era Thomas Kuhn, que trabajaba en la oficina de al lado, y cuyos escritos teóricos y filosóficos sobre cómo las teorías llegan a ser aceptadas y más tarde abandonadas influyeron mucho en mi propio enfoque. Otro fue Clifford Geertz, cuyo trabajo sobre la interpretación cultural lo sentí también muy afín, y de quien aprendí una enormidad en las conversaciones y correspondencia que mantuvimos a lo largo de los años. Finalmente estaba Richard Rorty, con quien coedité más tarde Philosophy in History (La Filosofia en la Historia), cuyos escritos sobre la racionalidad y la explicación - aun cuando no estaba de acuerdo con ellos- me parecieron de la mayor originalidad e importancia. 
L. M.: Ya que celebramos los 40 años de la publicación de su ensayo Meaning and Understanding in the History of Ideas (Sentido y Comprensión en la Historia de la Ideas), en términos de influencia ¿qué estaba pasando en ese campo durante aquellos años y cuál fue la reacción a su crítica?

Q. S.: Al principio, cuando publiqué mi manifiesto, había dos ortodoxias que quería desafiar. Una era principalmente marxista. Trataba las ideas como racionalizaciones de intereses y, por lo tanto, como carentes de valor independiente para explicar el comportamiento social. La otra ortodoxia, que era aun más extendida, postulaba que los historiadores de las ideas - y especialmente de las ideas morales y políticas - debían concentrarse en interpretar el así llamado canon de los textos clásicos; se sostenía que el estudio de ese canon nos ayudaría a responder lo que se consideraba eran las "preguntas perennes" del pensamiento moral y político.

Me pregunta también usted por la reacción que produjo en ese momento mi crítica a ambas escuelas de pensamiento. La mejor manera de responder es señalando que ese ensayo de 1969, a pesar de que sigue siendo lejos el más citado de mis trabajos, me resultó muy difícil de publicar, pues fue rechazado por todas las revistas académicas a las que inicialmente lo envié. Debo admitir que al releerlo hace poco para una conferencia ofrecida en Nueva York, para la celebración de sus cuarenta años, me pareció que su tono era excesivamente satírico y quizás también algo presuntuoso. De modo que puedo entender por qué los revisores se ofendieron. Pero sigo pensando que, tal como Kuhn dice que es de esperar, los intentos por desecharlo como algo que no ameritaba ser publicado pueden haberse debido en parte a un deseo natural de evitar que algunas ortodoxias poderosas fuesen atacadas con demasiada libertad.

\section{M.: ¿Cómo resumiría la intención de ese ensayo seminal?}

Q. S.: Yo tenía dos propósitos polémicos, pero ambos se fusionaron en mi deseo primordial de ver la historia de la filosofía estudiada de una manera más genuinamente histórica. Contra el planteamiento marxista que postula que las ideas no tienen valor explicativo independiente porque son meras racionalizaciones, argumenté que eso olvida 
cuán importante es en el debate político y moral el que seamos capaces de ofrecer justificaciones para las posturas que adoptamos. Argüí que incluso si se pudiera mostrar de alguna manera que las personas nunca se comportan de acuerdo con los principios que profesan, aun así necesitarían proceder de una manera congruente con la idea de que están actuando conforme a esos principios, pues de otro modo nunca podrían llegar a legitimar su comportamiento. Lo que esto muestra, planteé, es que aun cuando esos principios nunca funcionen como motivos, cumplen un papel en la explicación social, contrariamente a lo que señala la afirmación marxista de que su carácter sería puramente epifenoménico.

En contra de la idea de un canon de textos clásicos que abordan cuestiones supuestamente perennes, argüí que la filosofía no es meramente una disciplina en que se ofrecen diferentes respuestas a las mismas preguntas; es una disciplina en la que tanto las preguntas como las respuestas cambian todo el tiempo. Para entender cualquier texto es esencial discernir qué preguntas específicas está tratando de responder. Pero para poder llegar a ese tipo de discernimiento debemos situar los textos, incluso aquellos que parecen más trans-históricos, en los contextos sociales e intelectuales en los que originalmente fueron formulados.

Hoy en día estas cuestiones no son particularmente controvertidas, pero en los años que siguieron a la publicación de mi ensayo me involucraron en un debate en dos frentes - un debate, por cierto, para el cual yo no estaba del todo preparado para participar en él. Yo estaba expresando de hecho cierto escepticismo respecto a la tendencia de los estructuralistas a centrarse — para adoptar la distinción de Saussureen la langue más que en la parole. Estaba tratando de insistir en que el lenguaje debía ser visto no tanto como un sistema de signos, sino como una herramienta práctica para comunicarse con otros. Al mismo tiempo estaba abogando por una aproximación a la interpretación textual distinta de la preocupación tradicional por recuperar el significado de los textos. Me interesaban aún los significados, pero en un sentido diferente del término. Quería que los historiadores se concentraran en lo que los autores de los textos podrían haber querido decir mediante el acto de escribirlos. Estaba abogando, en otras palabras, por un énfasis no en el significado sino en los actos-de-habla (speech-acts), en la necesidad de entender lo que los escritores de los textos están haciendo al escribirlos 
- ya sea que estén sosteniendo una posición particular a favor de un argumento, o desafiándolo, o desarrollándolo o cuestionándolo, o respaldándolo o satirizándolo, y así sucesivamente, a través de la miríada de actos-de-habla que cualquier acto de comunicación complejo pueda abarcar.

L. M.: Con la ventaja de una mirada retrospectiva, ¿por qué cree usted que el énfasis en la importancia del lenguaje y el contexto ha cambiado la manera en que miramos hoy la historia intelectual?

Si es que esta perspectiva ha ayudado realmente a producir un cambio, creo que eso debe obedecer en parte al hecho de que en nuestras sociedades multiculturales y posmodernas estamos menos inclinados a creer en cánones establecidos y grandes narrativas. Hoy en día los historiadores de las ideas están mucho más dispuestos a aceptar que todas las proposiciones que encontramos, incluso en los trabajos de filosofía más abstractos, se entienden mejor como argumentos dirigidos a temas específicos en debates específicos en tiempos específicos, y que la tarea del historiador es tratar de recuperar los términos de esos debates.

L. M.: En 1975 John Pocock publicó The Machiavellian Moment (El Momento Maquiavélico) y tres años después usted publicó The Foundations of Modern Political Thought (Los Fundamentos del Pensamiento Político Moderno). ¿De qué manera contribuyeron ambos trabajos al debate metodológico?

Q. S.: El libro de John Pocock es una obra maestra y merecidamente ha tenido amplia influencia, pero es un libro muy diferente del que yo escribí. A John le gusta destacar el poder del lenguaje en sí, y describe la influencia de diferentes vocabularios políticos y morales en la configuración de lo que él llama la tradición atlántica del pensamiento político. A mí me gusta darles mayor énfasis a la agencia y a los textos individuales. Como ya he señalado, para mí la cuestión central respecto a la interpretación es siempre sobre lo que el autor de un texto en particular podría haber estado haciendo al escribirlo. Trato, en esencia, a todos los textos como elementos de un diálogo, como intervenciones en alguna discusión pre-existente a la que estos autores están intentando contribuir de alguna manera. Para mí, el deber principal de 
un intérprete es tratar de recuperar la naturaleza exacta de la contribución que cada texto está intentando hacer. La destreza y el saber del historiador deben ser desplegados de manera tal que le permitan percibir el espectro del debate, identificar qué argumentos específicos están siendo utilizados, y de esta manera situar en su lugar apropiado los textos específicos en que él o ella están interesados.

L. M.: El concepto de libertad tiene una tradición clásica de larga data que usted aborda en Liberty before Liberalism (La Libertad antes del Liberalismo), ¿cuál es la principal diferencia entre el concepto de libertad republicano y el liberal?

Q. S.: Las visiones republicana y liberal de la libertad son similares en tanto ambas tratan el concepto de libertad como un concepto negativo. Con esto quiero decir que están de acuerdo en señalar que la presencia de la libertad está marcada por la ausencia de algo. Donde difieren es en las versiones rivales que dan acerca de la naturaleza de la ausencia que puede decirse constituye la presencia de la libertad. Para el liberal se trata de la ausencia de interferencia, una ausencia de los tipos de impedimentos que nos imposibilitan para ejercer nuestros poderes a voluntad. Para el republicano, la ausencia que marca la presencia de la libertad es la ausencia de dependencia. Eres libre, de acuerdo con la teoría republicana, si y sólo si no dependes de la voluntad arbitraria, y por lo tanto de la buena voluntad, de alguien más.

El significado de la distinción es que habrá muchas circunstancias en que un republicano verá violaciones a su libertad donde el liberal no ve ninguna. Para los liberales no tiene sentido hablar de tales transgresiones a menos que podamos señalar un impedimento específico que interfiera con el ejercicio de los poderes de un individuo. En cambio lo que más importa a los republicanos es que si usted depende de la voluntad de otra persona — si, por ejemplo, usted está a merced de un amo o gobernante con poderes arbitrarios-, su voluntad entonces ya habrá sido socavada, aun cuando no haya habido interferencia real con su comportamiento. Si usted es dependiente, entonces cualquier acción que usted haga tendrá el carácter de un mero permiso, ya que su amo o gobernante siempre podrá interferir si así lo desea. Es más, apenas usted adquiere conciencia de que éste es su predicamento, esto tendrá el efecto de limitar aún más su rango de opciones, puesto que ahora, con toda pro- 
babilidad, usted autocensurará su propia conducta con la esperanza de evitarse problemas. Es muy poco probable que una persona que vive en un estado de dependencia se sienta capaz de decirle la verdad al poder.

Una manera diferente y quizás más iluminadora para contrastar ambas teorías sería decir que mientras para los republicanos la libertad es esencialmente una cuestión de estatus, para los liberales es simplemente un predicado de las acciones. Lo que importa para los republicanos es si usted es o no un ejemplo de lo que el derecho romano llamaba un liber homo, un hombre o mujer libre, alguien que no depende de la voluntad de un gobernante o amo como le sucede a un esclavo. Lo que les importa a los liberales es simplemente si tiene usted o no la posibilidad de ejecutar las acciones que están en su poder, o si existe algún impedimento para que las realice.

A propósito, debería añadir que tengo cada vez más dudas respecto a la conveniencia de etiquetar estas posiciones rivales como 'liberal' y 'republicana' respectivamente. Durante el apogeo de las teorías republicanas en la Europa clásica y renacentista había muchos pensadores que defendían la llamada teoría republicana de la libertad, sin ser republicanos en el sentido estricto de oponerse a la monarquía como forma de gobierno. Incluso, a medida que la tradición liberal evolucionó en Europa occidental, hubo muchos que se confesaban liberales -incluyendo figuras tan prominentes en el siglo XIX como Benjamin Constant y John Stuart Mill—, quienes sin embargo adherían a una visión republicana de la libertad, tal como claramente lo hace Mill en su tratado The Subjection of Women (La Sujeción de la Mujer), de 1869.

Me parece que la mejor manera de caracterizar la distinción crucial en la que estoy interesado es simplemente recordar que mientras algunos filósofos creen que las relaciones de dominación y dependencia por sí mismas restan libertad, otros insisten en que no puede haber pérdida de libertad en la ausencia de un acto identificable de interferencia. No importa mucho cómo etiquetemos estas dos posturas; lo que importa es la distinción misma. La razón por la que importa es que en tanto la mayoría de los teóricos contemporáneos (por lo menos en el mundo anglófono) adhiere actualmente a la segunda de estas alternativas, me parece que sería mucho mejor si suscribieran la primera.

L. M.: ¿Ve algunas raices comunes entre el liberalismo y el republicanismo? ¿Cuáles son sus principales diferencias? 
Q. S.: Por cierto, las dos escuelas de pensamiento tienen algo crucial en común: ambas están tratando de explicar lo que consideran es la esencia de la acción libre. Además concuerdan, como hemos visto, en que la libertad es esencialmente un concepto "negativo": que la presencia de la libertad se caracteriza siempre por la ausencia de algo. La principal diferencia entre ellas es que mientras los liberales dicen que la esencia de la libertad consiste en la ausencia de interferencia, los republicanos argumentan que su esencia consiste en la ausencia de relaciones de dominación y dependencia.

Con todo, al plantear el punto de esta manera queda de relieve una similitud adicional entre ambas teorías, que a mi juicio también revela por qué, definitivamente, se debe preferir la teoría 'republicana'. Si usted acepta que lo que básicamente priva de libertad es la dominación y la dependencia, entonces es fácil acomodar la visión 'liberal' según la cual la libertad también puede ser sustraída por actos de interferencia. Pero si usted insiste en que lo fundamental es la ausencia de interferencia, entonces es muy difícil acomodar la visión 'republicana' sobre la importancia de la dependencia. Los escritores a los que he llamado republicanos no niegan, por supuesto, que si a usted se le impide ejercer sus poderes (por ejemplo, si usted es enviado a prisión), su libertad habrá sido entonces quebrantada. Simplemente están afirmando que estas violaciones no nos entregan la esencia de la libertad, que para ellos tiene que ver con cuestiones sobre el control. Si sus actos, según el análisis 'republicano', están bajo el control de su propia voluntad, luego usted es libre; si están bajo el control de otro, entonces usted no es libre porque es un esclavo.

L. M.: ¿Podría explicarnos por qué en su último libro Hobbes and Republican Liberty (Hobbes y la Libertad Republicana) vuelve a la importancia de Hobbes y su contexto?

Q. S.: Está en lo correcto cuando dice que en mi libro más reciente 'vuelvo' a Hobbes, puesto que ya era el héroe de mi Reason and Rhetoric in the Philosophy of Hobbes, de 1996, y de mi Hobbes and Civil Science, de 2002. La razón principal para volver a Hobbes fue que me pareció que no sería ir demasiado lejos afirmar que dentro de la tradición anglófona de la teoría política él suministró el pivote en torno al cual ha girado el debate que he estado esbozando. Antes de que 
Hobbes publicara su Leviatán en 1651, es difícil pensar que alguien refutara la afirmación de que la libertad es esencialmente una cuestión de independencia. La definición formal de libertad que entregó Hobbes en el capítulo 21 de su Leviatán, como nada más que la ausencia de impedimentos externos al ejercicio de nuestros poderes a voluntad, significó un hito en la historia.

L. M.: ¿Por qué la historia del pensamiento político debiera hoy en día ser relevante para nosotros?

Q. S.: No creo que nuestra motivación básica como historiadores debería consistir en que nuestros estudios sean "relevantes" para las preocupaciones contemporáneas. Sin embargo, los historiadores de las ideas a veces hacen descubrimientos cuya importancia y relevancia pueden haber sido pasados por alto. Como debe ser obvio a estas alturas, pienso que éste ha sido el caso en las discusiones respecto a la mejor forma de entender el concepto de libertad. La tradición liberal de la teoría política se desarrolló en forma tal que anuló en gran parte la comprensión rival del concepto. Ahora que los historiadores están trayendo nuevamente a la luz la teoría rival, nos están mostrando a su vez que bien vale la pena reconsiderar esta teoría, y que ésta tiene una importancia clara e inmediata para la vida contemporánea.

Me parece que esto proporciona un modelo de cómo nuestros estudios históricos pueden tener una 'relevancia' sin que nosotros tengamos que distorsionarlos al momento de exhibirla. A todos nos resulta difícil, creo, evitar que nos encandile nuestra herencia intelectual. Cuando analizamos y reflexionamos sobre nuestros conceptos normativos es fácil sucumbir a la creencia de que las maneras de pensar sobre ellos que nos han sido legadas por la corriente principal de nuestra tradición intelectual deban ser las maneras de pensar acerca de ellos. Como he estado diciendo, esto es lo que me parece que ha sucedido en el caso de las formas imperantes de pensar sobre el concepto de libertad. Una de las funciones del historiador de las ideas es, por lo tanto, actuar como una especie de exorcista, alguien cuyo conocimiento del pasado puede ayudar a impedir que seamos fácilmente encandilados.

L. M.: Finalmente, ¿se considera un historiador, un historiador de las ideas o un historiador de la filosofía? ¿O quizás todas las anteriores? 
Mi compromiso existencial es con el estudio del pasado. Me veo a mí mismo como un historiador y, específicamente, como un historiador de la filosofía, en particular de la filosofía moral y política. Pero también creo que a menos que nuestros estudios históricos tengan algún punto filosófico, corren el peligro de caer en algún tipo de "anticuarianismo" fomentado hoy en día por el culto a la "investigación" en las universidades. De modo que después de todo, quizás, tengo el temperamento de un filósofo, pues lo que más me interesa es que nuestros estudios históricos nos provean de un entendimiento que nos permita reflexionar con nuevos ojos sobre nuestras dificultades actuales. $\square$ 